\title{
Role of laminin bioavailability in the astroglial permissivity for neuritic outgrowth
}

\author{
MARCIENNE TARDY \\ INSERM U-421, IM3, Medical Faculty and Biochemistry Department \\ CHU Henri Mondor, 94010 Creteil, France \\ Manuscript received on October 3, 2002; accepted for publication on October 10, 2002; \\ presented by LENY A. CAVALCANTE
}

\begin{abstract}
The mechanisms involved in the failure of an adult brain to regenerate post-lesion remain poorly understood. The reactive gliosis which occurs after an injury to the CNS and leads to the glial scar has been considered as one of the major impediments to neurite outgrowth and axonal regeneration. A glial scar consists mainly of reactive, hypertrophic astrocytes. These reactive cells acquire new properties, leading to A non-permissive support for neurons. Astrogial reactivity is mainly characteriized by a high overexpression of the major component of the gliofilaments, the glial fibrillary acidic protein (GFAP). This GFAP overexpression is related to the astroglial morphological response to injury. We hypothesized that modulation of GFAP synthesis, reversing the hypertrophic phenotype, might also reverse the blockage of neuritic outgrowth observed after a lesion. In this article, we review findings of our group, confirming our hypothesis in a model of lesioned neuron-astrocyte cocultures. We demonstrate that permissivity for neuritic outgrowth is related to phenotypic changes induced in reactive astrocytes transfected by antisense GFAP-mRNA. We also found that this permissivity was related to a neuron-regulated extracellular laminin bioavailability.
\end{abstract}

Key words: astrogliosis, neuro-glia interactions, neurite outgrowth, neuronal migration, laminin, metalloproteinases.

\section{INTRODUCTION}

Astrocytes are the most numerous cellular components of the brain. Despite their number and their contribution to brain development and function, the consequences of their dysfunction on the physiology of the nervous system have only been considered recently. Astrocytes have been involved in many functions including control of brain development and homeostasis (for a review see Tardy 1991), CNS im-

Correspondence to: Dr. Marcienne Tardy

Inserm U-421, Medical Faculty

8 , rue du Gal Sarrail

94010 CRETEIL (France)

Fax: $33+149813709$

E-mail: tardy@im3.inserm.fr munity, and in regulation of development, function and efficiency of the synapse (Pfrieger and Barres 1996). Their implication in a defence mechanism against oxydative stress has been reported (Desagher et al. 1996). It has been shown that astrocytes may provide new means of communication in the nervous system (Smith 1994, Verkhratsky et al. 1998). Subpopulations of these cells have been described and as many different types of astrocytes may exist as neurons (Kimelberg 1995).

The reactive astrocyte, a hypertrophied astroglial phenotype, is found mainly in the vicinity of a lesion, constituting the most characteristic response of the CNS to destructive tissue injury, the glial scar. 
These cells are typified by cytoplasmic hypertrophy associated with a profusion of long, thick processes. The most striking ultrastructural finding, however, is the presence of bundles of intermediate filaments which at times appear to fill the entire cytoplasmic compartment (Hozumi et al. 1990). These filaments are often heteropolymers, largely consisting of GFAP and, at a lesser degree, of vimentin (Ridet et al. 1997). The glial scar constitutes a physical and chemical barrier which isolates the intact tissue, but also contributes to the failure for recovery post-injury (Bush et al. 1999). Reactive astrocytes, however, may also produce trophic factors benefic for axonal regrowth. Whether these elements are beneficial or detrimental for recovery remains enigmatic. In the developing brain, the growth of axons is guided by astrocytes (Silver et al. 1993). In contrast, in the adult brain, axons do not regrow after axotomy and, in this regard, the inhibitory role of the astroglial scar has been well documented (Reier and Houle 1988). Many phenotypic changes have been observed in astroglial cells during their maturation, among them, a decrease in molecules known to promote axonal growth, like laminin (Rivas et al. 1992), NCAM, heparan sulfate proteoglycan (HSPG) have been reported (McKeon et al. 1995). In the opposite, molecules like chondroitin sulfate proteoglycan (CSPG) or Tenascin, known for inhibiting neurite outgrowth, increase during astroglial maturation (Faissner and Steindler 1995).

One major change in the astroglial phenotype during maturation as well as during astroglial reactivity, is associated with the increase in the major component of their intermediate filament, the glial fibrillary acidic protein (GFAP). This major event, directly associated with morphological changes (Tardy et al. 1993), suggested its involvement in the astroglial functional shift from neurite-promoting (permissive), to neurite-inhibiting (non-permissive) elements.

Mechanically lesioned neurons/astrocytes primary cocultures presenting an astrogliosis around the lesion site, reproduce adequately in vitro, the phenomena characterized in vivo. This model was used to determine whether a triggered decrease in GFAP could affect neurite outgrowth. Antisense GFAP-mRNA decreased GFAP synthesis and the consecutive phenotypic changes were associated with a functional shift towards neurite-promoting elements. Molecular studies showed a regulation of a major ECM molecule by the astrocytes, in relation to the expression of a member of the family of zinc-dependent metalloproteinases (MMPs) whose activities are involved in tissue remodeling (Yong et al. 1998).

\section{WHAT IS A REACTIVE ASTROCYTE?}

GFAP and glutamine synthetase (GS) (for a review see Suarez et al. 2002), are respectively a structural and a functional astroglial marker which allowed the identification of functional mature astrocytes (Dell'Albani et al. 1990). Post trauma, in the vicinity of the lesion site, and sometimes even faraway astrocytes are turned reactive and present a hypertrophic phenotype consisting in an enlarged soma and thickened processes, highly labeled with GFAP (Eng and Ghirnikar 1994, Tardy et al. 1993). Some of these cells coexpress vimentin, an intermediate filament protein, normally found in immature astrocytes, underlining that a population of reactive astrocytes share some features with both immature and adult astrocytes. This underlines also the existence of different populations of reactive astrocytes and raises the question of whether this is due to a heterogeneous reactivity of a subpopulation of mature astrocytes, or of astroblasts, or both. Since stem cells are widely present in the adult brain, a lesion could give rise, starting from these precursor cells, to reactive astrocytes under the stimulation of environmental factors. As an example, transforming growth factor $\alpha$ (TGF $\alpha)$, a member of the epidermal growth factor (EGF) family, has been recently shown to trigger astrogliosis in vivo (Rabchevsky et al. 1998, Junier 2000). Many other factors released by surrounding mature astrocytes [ciliary neurotrophic factor (CNTF), glia maturation factor (GMF), S-100 protein], or from activated microglia (interleukines, tumor necrosis fac- 


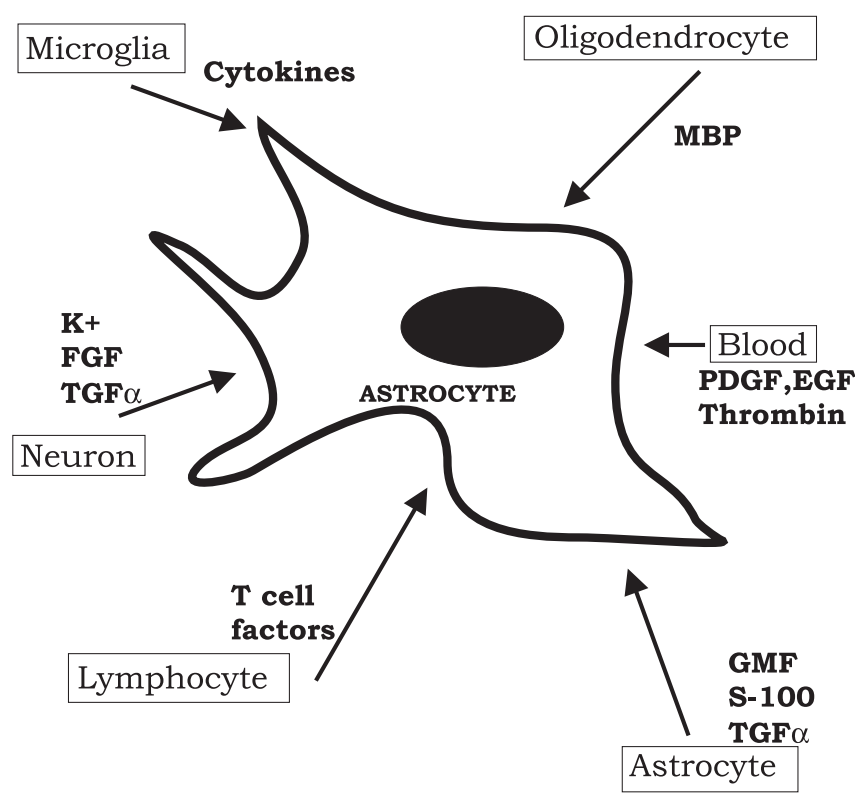

Fig. 1 - Factors triggering the astroglial reactivity in response to an injury in the adult CNS. MBP (myelin basic protein), GMF (glial maturating factor), TGF $\alpha$ (transforming growth factor $\alpha$ ), FGF (fibroblast growth factor), EGF (epidermal growth factor), PDGF (platelet-derived growth factor).

tor, interferon-gamma), lesioned neurons (fibroblast growth factor, potassium, ATP), oligodendrocytes (myelin basic protein), from blood (thrombin, epithelial growth factor (EGF), platelet-derived growth factor (PDGF), steroids, insulin), endothelial cells (endothelin, ATP), and activated lymphocytes (Fig. 1). Other factors including the prion protein, fibronectin, putrescine and prostaglandines (Kimelberg and Norenberg 1994) have also been implicated.

Reactive astrogliosis is accompanied by an induction and an upregulation of many proteins with potential biological effects (Fig. 2). For instance, basic fibroblast growth factor (bFGF) stimulates the production of nerve growth factor (NGF) and protects against excitotoxic injury, but also contributes to the excessive neurite sprouting and dystrophic neurite formation observed in Alzheimer disease (for a review see Norenberg 1994). It becomes evident that reactive gliosis varies depending on the nature of the injury, and the microenvironment of the in- jury site. Reactive astrocytes are metabolically activated cells. As an example, glutamine synthetase, a metabolic astroglial marker, essential for glutamate and ammonia neutralization, (Tardy 1991), cellular function and brain detoxification, has also been found modified in various pathological conditions associated with astroglial reactivity. Increased in the natural scrapie of the sheep (Lefrançois et al. 1994), it may illustrate an attempt by astrocytes to maintain and control the cerebral homeostasis. Reduced in senile dementia brains of the Alzheimer type, it underlines a dysfunction of the astroglial metabolism, might reflect oxidative damage and might have severe consequences on the pathological cascade of events (Le Prince et al. 1995).

\section{INHIBITION OF ASTROGLIAL HYPERTROPHY INDUCES FUNCTIONAL CHANGES, BENEFICIAL FOR AXONAL REGROWTH}

To analyze in vitro the interactions between neurons and astrocytes in the vicinity of a mechani- 


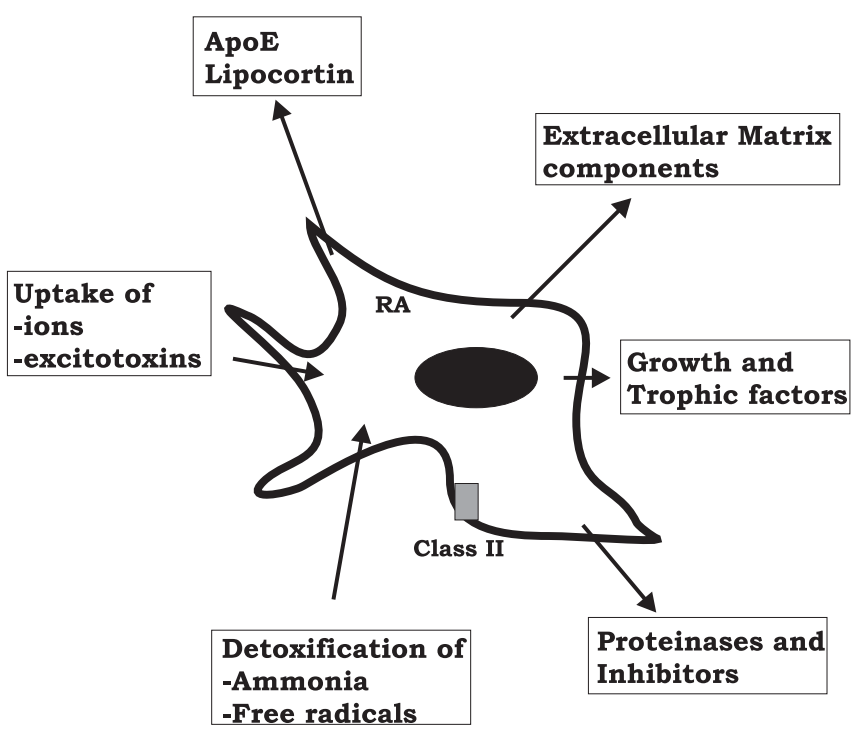

Fig. 2 - Functional properties of reactive astrocytes (RA). Reactive astrocytes produce growth and trophic factors (NGF, FGF, PDGF, CNTF, IGF...), interact with remodeling of Extracellular Matrix (glycoproteins, proteinases and inhibitors), with Inflammation/ Immunity compounds, (class II histocompatibility antigens, apoE, lipocortin) and with detoxification and control of homeostasia (excitotoxins, ions, free radicals).

cal lesion, we chose mechanically lesioned rodent neuron-astrocyte cocultures. Hypertrophic astrocytes were present, neighboring the lesion and neurons were absent from the area of lesion and from its surroundings. These reactive, hypertrophic astrocytes appeared, therefore, as a non-permissive substrate and the coculture model used could be considered valid to study the consequences of astroglial reactivity on axonal growth, in spite of the absence of the three dimensions of a tissue. Transfection of an antisense for GFAP-mRNA in the lesioned coculture, in order to modulate the astrocytic response to the injury, reduced cell hypertrophy and decreased the capacity of the cells to translate GFAP-mRNA (Lefrançois et al. 1997).

After such antisense treatment, neuronal cell bodies and neurites were reobserved over astrocytes of the lesion border and neurites projected into the lesion site. The expression of GAP-43, associated with nerve sprouting (Schreyer and Skene 1991) was increased and supports our working hypothesis that astroglial hypertrophy plays a role in the failure of axonal regeneration at a site of injury. Could this modulation in GFAP synthesis have presented the formation of a physical barrier to neuron migration or axon growth? That cannot be excluded but, more probably, hypertrophic astrocytes offer a poor substratum for axonal regrowth. Astrocytes synthesize many components of the extracellular matrix that play major roles in axonal outgrowth. Some of them are inhibitory (proteoglycans or tenascin), others are promoters like laminin. With regard to laminin, our results point out two pattern of laminin immunoreactivity which bear different potentials for axonal growth. A punctate patterns of intracellular laminin was associated with non-permissive conditions, whereas fibrillar pattern of an extracellular laminin network was related to the permissive conditions (see also Garcia-Abreu et al. 1995). Laminin, by its increased synthesis and its distribution, 
therefore, may be one element involved in the lack of inhibition after antisense treatment.

\section{MANIPULATING THE LAMININ BIOAVAILABILITY INDUCES CHANGES IN PERMISSIVITY OF NEURITE OUTGROWTH}

A dynamic role for the overlaying laminin in neuronal migration and neurite outgrowth was confirmed when permissive cocultures were treated with anti-laminin antibodies (Costa et al. 2002). These antibodies which recognize the astroglial laminin blocked a large part of neurite outgrowth and inhibition of neuronal migration to the lesion site, whereas an antibody against tenascin $\mathrm{C}$, another component of the extracellular matrix (Faissner and Steindler 1995), did not. This indirect evidence was supported by a more direct one, consisting in the addition of soluble, native laminin to the coculture, which promotes neurite outgrowth and neuronal migration. These results do not exclude a soluble form of laminin released by the astroglial monolayer which may contribute to the permissivity in addition to the overlaying network.

\section{SWITCH TO A PERMISSIVE SYSTEM FOR NEURITE OUTGROWTH IS RELATED TO A RAPID AND CONSTANT INCREASE IN LAMININ}

Laminin level increased rapidly in the permissive antisense-treated cocultures, and remained high. A reverse relationship between GFAP and laminin levels was observed in the permissive cocultures. In addition, we found that an enhanced laminin level was under neuronal control and consequent to either secreted factors or to cell interactions. Such signals may regulate both, laminin synthesis and extracellular availability, in order to improve neurite outgrowth (Costa et al. 2002).

\section{CHANGES IN LAMININ STRUCTURE AND LOCALIZATION MIGHT PARTICIPATE IN PERMISSIVITY}

The switch from a non-permissive to a permissive support for neuronal migration and neurite outgrowth is correlated with a differential pattern of laminin expression.
A laminin labeled astroglial monolayer, a dense and regular overlaying network, characterizes the control unlesioned cocultures. Mechanical lesion modified the labeling distribution in the monolayer, where it significantly decreases, out of a population of large and flat astrocytes around the lesion border which remained labeled with punctate intracellular spots (Lefrançois et al. 1997). The laminin labeled network, overlaying the astroglial lesioned monolayer, appeared unstructured and a dense labeled network was concentrated along the lesion border. Antisense treatment restructured the labeled network, underlining that permissivity involves particular patterns of laminin expression (Costa et al. 2002).

\section{LAMININ BIOAVAILABILITY INVOLVES CHANGES IN PROTEASE/ANTIPROTEASE RATIO IN PERMISSIVE CONDITIONS}

The permissive process, observed in the lesioned antisense treated cocultures, might be associated with modulations of the extracellular matrix components by proteinases (Gomez et al. 1997). Among them, matrix metalloproteinases MMP-2 expression, have been involved in this type of process (Campbell and Pagenstecher 1999, Lukes et al. 1999). Associated with our permissive model, a net decrease of MMP-2 expression and activity and an increase in its endogenous inhibitor TIMP-2 expression are observed. The ratio between this metalloproteinase and its endogenous inhibitor might be directly involved in permissive conditions, in the observed laminin stabilization and in cell-matrix interactions.

\section{CONCLUSIONS AND PERSPECTIVES}

In conclusion, blockage of cellular hypertrophy in reactive astrocytes by antisense GFAP-mRNA, induces a major functional alteration, revealed by modified astrocyte-neuron interactions in cocultures. This functional alteration relates to changes in secreted and/or membrane-bound proteins. How GFAP synthesis might be linked to these apparently very different phenomena remains an open question. Recently, GFAP null astrocytes have been pre- 
sented as a favorable substrate for neuronal survival and neurite growth, which support our observations (Menet et al. 2000). As a working hypothesis, one may consider changes in the intracellular transport in which gliofilaments are involved or an indirect modulation of genetic transcription.

The observed increase in laminin level, bioavailability and in laminin network structure and distribution, under neuronal control, might result from secreted factors or cell to cell interactions and remained to be determined. Such signals may regulate both laminin synthesis and extracellular laminin availability in order to improve neurite outgrowth. Neuron-glia interactions are believed to play an important role in the regulation of axonal growth and guidance, during both, development and regeneration. These interactions are mediated by extracellular components promoting polymerization or stabilization of elements of the neuronal cytoskeleton. Laminin appears to be a serious candidate for such an interplay. With respect to cell migration, neural cell may require balanced MMPs activities in order to migrate to the scarred area. New axonal growth and synaptic reconnections need to be established in a lesioned brain and their extension through the brain matrix may also require a new MMPs/TIMPs ratio. The decreased ratio observed in our in vitro permissive conditions may actively contribute to the increased laminin steady-state level report here, which, probably in addition with other components of the extracellular domain, assist regrowth permissivity.

\section{ACKNOWLEDGMENTS}

This work received its financial support from the Institut National de la Santé et de la Recherche Médicale (INSERM).

\section{RESUMO}

Os mecanismos envolvidos na falha de um encéfalo adulto a regenerar após uma lesão permanecem escassamente compreendidos. A gliose reativa que ocorre após uma injúria ao SNC e leva à "cicatriz" glial consiste principalmente de astrócitos reativos, hipertróficos. Estas células reativas adquirem novas propriedades, levando a um suporte não-permissivo para neurônios. A reatividade astroglial é caracterizada principalmente por elevada super-expressão da principal componente dos filamentos gliais, a proteína acídica fibrilar glial (GFAP). Esta superexpressão de GFAP está relacionada à resposta morfológica astroglial à injúria. Nós levantamos a hipótese de que a modulação da síntese de GFAP, revertendo o fenótipo hipertrófico, poderia também reverter o bloqueio do crescimento neurítico observado após uma lesão. Neste artigo, nós revisamos achados de nosso grupo, confirmando nossa hipótese em um modelo de co-cultura de neurônios lesados e astrócitos. Nós demonstramos que a permissividade para crescimento neurítico está relacionada a mudanças induzidas em astrócitos reativos transfectados com o mRNA anti-senso para GFAP. Nós também observamos que esta permissividade estava relacionada com a bio-disponibilidade de laminina extra-celular.

Palavras-chave: astrogliose, interações neuro-gliais, crescimento neurítico, migração neuronal, laminina, metalo-proteinases.

\section{REFERENCES}

Bush TG, Puvanachandra N, Horner CH, Polito A, Ostenfeld T, Svendsen CN, Mucke L, Johnson MH AND Sofroniew MV. 1999. Leukocyte infiltration, neuronal degeneration and neurite outgrowth after ablation of scar-forming, reactive astrocytes in adult transgenic mice. Neuron 23: 297-308.

Campbell IL and Pagenstecher A. 1999. Matrix metalloproteinases and their inhibitors in the nervous system: the good, the bad and the enigmatic. Trends Neurosci 22: 285-287.

Costa S, Planchenault T, Charriere-Bertrand C, Mouchel Y, Fages C, Sharon J, Lefrançois T, Barlovatz-Meimon G and Tardy M. 2002. Astroglial permissivity for neuritic outgrowth in neuronastrocyte cocultures depends on regulation of laminin bioavailability. Glia 37: 105-113.

Dell'Albani DF, Kaczmarek L, Messina L, Spampinato G, Avolar, Messina A and Giuffrida Stella AM. 1990. Glial Fibrillary Acidic Protein mRNA and glutamine synthetase activity after nervous system injury. J Neurosci Res 26: 251-257.

Desagher S, Glowinski J and Premont J. 1996. Astro- 
cytes protect neurons from hydrogen peroxide toxicity. J Neurosci 16(8): 2553-2562.

ENG LF AND GHIRNIKAR RS. 1994. GFAP and astrogliosis. Brain Pathol 4: 229-237.

FAissner A AND Steindler DA. 1995. Boundaries and inhibitory molecules in developing neural tissues. Glia 13: 233-254.

Garcia-Abreu J, Cavalcante LA and Moura Neto V. 1995. Differential patterns of laminin expression in lateral and medial midbrain glia. Neuroreport 6: 761-764.

Gomez DE, Alonso DF, YoshiJi H AND Thorgeirsson UP. 1997. Tissue inhibitors of metalloproteinases structure, regulation and biological functions. Eur J Cell Biol 74: 111-122.

Hozumi I, Chiu FC and Norton WT. 1990. Biochemical and immunocytochemical changes in GFAP after stab wound. Brain Res 524: 64-71.

JUNIER MP. 2000. What role(s) for TGFalpha in the central nervous system? Prog Neurobiol 62: 443-473.

Kimelberg HK. 1995. Receptors on astrocytes - What possible functions? Neurochem Int 26(1): 27-40.

Kimelberg HK AND Norenberg MD. 1994. Astroglial response to CNS trauma. In SALzMAN SK AND FADEN AI (eds). The Neurobiology of central nervous system trauma. New York: Oxford University Press: 193-208.

Lefrançois T, Fages C, Peschanski M and Tardy M. 1997. Neuritic outgrowth associated with astroglial phenotypic changes induced by anti-sense Glial Fibrillary Acidic Protein (GFAP) mRNA in injured neuron-astrocyte cocultures. J Neurosci 17(11): 4121-4128.

Lefrancois T, Fages C, Brugere-Picoux J And Tardy M. 1994. Astroglial reactivity in natural scrapie of sheep. Microb Pathogenesis 17: 283-289.

Le Prince G, Delaere P, Fages C, Lefrancois T, Touret M, Salanon M and Tardy M. 1995. Glutamine synthetase (GS) expression is reduced in senile dementia of the Alzheimer type. Neurochem Res 20: 859-862.

Lukes A, Mun-Bryce S, Lukes M and RosenberG GA. 1999. Extracellular matrix degradation by metalloproteinases and central nervous system diseases. Mol Neurobiol 19: 267-284.
McKeon RJ, HöKe A AND Silver J. 1995. Injuryinduced proteoglycans inhibit the potential for laminin-mediated axon growth on astrocytic scars. Exp Neurol 136: 32-43.

Menet V, Gimenez Y, Ribotta M, Saudillon F And Privat A. 2000. GFAP null astrocytes are favorable substrate for neuronal survival and neurite growth. Glia 313: 267-272.

Norenberg MD. 1994. Astrocyte responses to CNS injury. J Neuropath Exp Neur 53: 213-220.

Pfrieger FW ANd Barres BA. 1996. New views on synapse-glia interactions. Curr Opin Neurobiol 6: 615-621.

Rabchevsky AG, Weinitz JM, Coulpier M, Fages C, Tinel M And Junier MP. 1988. A role for transforming growth factor alpha as an inducer of astrogliosis. J Neurosci 18: 10541-10552.

ReIer PJ AND Houle JD. 1988. The glial scar: its bearing, on axonal elongation and transplantation approaches to CNS repair. In Advances in neurology: functional recovery in neurological diseases WAKSMAN SG (ed.) New York: Raven, 87-138.

Ridet JL, Malhotra SK, Privat A and Gage FH. 1997. Reactive astrocytes: cellular and molecular cues to biological function. Trends Neurosci 12: 570-577.

Rivas RJ, Burmeister DW AND GoldBerg DJ. 1992. Rapid effects of laminin on the growth cone. Neuron 8: $107-115$.

Schreyer DJ AND Skene JH. 1991. Fate of gap-43 in ascending spinal axons of DRG neurons after peripheral nerve injury: delayed accumulation and correlation with regenerative potential. J Neurosci 11: 3738-3751.

Silver J, Edwards MA And Levitt P. 1993. Immunocytochemical demonstration on early appearing astroglial structures that form boundaries and pathways along axons tracts in the fetal brain. J Comp Neurol 328: 415-436.

Sмiтh SJ. 1994. Neuromodulatory astrocytes. Curr Biol 4: 807-810.

Suarez I, Bodega G and Fernandez B. 2002. Glutamine synthetase in brain: effect of ammonia. Neurochem Int 4: 123-142.

TARDY M. 1991. Astrocyte et homeostasie. M/S 8(7): 799-804. 
Tardy M, Le Prince G, Babajko S, Riol H, Fages C AND Rolland B. 1993. GFAP gene expression in normal and reactive astrocytes. Biology and Pathology of Astrocyte-neuron Interactions. FEDOROFF ET AL. (eds). New York: Plenum, p. 153-161.
Verkhratsky A, Orkrand RK and Kettenmann H. 1998. Glial calcium: homeostasis and signaling function. Physiol Rev 78: 99-142.

Yong VW, Krekoski CA, Forsyth PA, Bell R AND EDWARD DR. 1998. Matrix metalloproteinases and diseases of the CNS. Trends Neurosci 21: 75-80. 